\title{
Conversational learning integration in technology enhanced classrooms
}

\author{
Yacine Atif \\ Faculty of Information Technology, UAE University, Al Ain, United Arab Emirates
}

\section{A R T I C L E I N F O}

\section{Article history:}

Available online $\mathrm{xxxx}$

\section{Keywords:}

Conversational learning

Future classroom

Learning design

Assessment

Learning technology

Collaborative learning

\begin{abstract}
A B S T R A C T
Today's college students have grown up with technology. These digital natives typically gravitate toward group activities in technology embedded social contexts. However, despite this multidimensional evolution, little has changed in conventional classrooms where they build their education experience. We investigate learning models in a classroom environment which still remains the main driver of education today. We describe a conversational learning model based on group activities which involve multi-party conversations. We implement this model in a technology-enhanced studio-classroom to "visualize" conversations which otherwise would remain abstract to learners. Teachers are empowered with instructional patterns to guide their changing role in this novel classroom environment. Based on standard assessment indicators, we conduct an experimental analysis which results show interesting tradeoffs of learning performance that favor the proposed conversational learning approach compared to those obtained from conventional instruction.
\end{abstract}

() 2012 Elsevier Ltd. All rights reserved.

\section{Introduction}

Technology has revolutionized our culture. Children are born and raised in an environment where virtually anything can be reached at Internet speed. Our education system is rushing to catch up with these profiles of learners through the deployment of technology-enhanced learning facilities. An increasing number of institutions have effectively integrated technology in their learning environments to support novel instructional approaches and improve teamwork, in an effort to reform education (Schrum \& Levin, 2010). During the last decades though, little has changed in conventional classrooms despite the rapid and wide proliferation of technology, and the soaring enthusiasm of learners for smart gadgets (Tantatsanawong, Kawtrakul, \& Lertwipatrakul, 2011). The lack of sound reference models may have contributed to this slow move to bridge the digital gap in our classrooms. Furthermore, teachers need to be comprehensively empowered to adjust their instruction capability in any envisioned classroom of the future.

A contemporary education psychologist argues that learners are not just "passive empty vessels waiting to be filled with knowledge by the experts" (Richtel, 2011). Learners bring their own prior experiences, knowledge and beliefs to the classroom and thus they shape the way in which they construct their own individual knowledge, mediated, but not exclusively provided, by the teacher (De Freitas et al., 2010). The same education psychology expert suggests that classrooms are expected to be "student-centered, promote constructivist activities and communities of practice". Hence, future learning spaces (Brown, 2005) need to be reconfigu-

E-mail address: Yacine.Atif@uaeu.ac.ae rable to meet these changing learning modes. Traditional teaching tends to present concepts that are already explained in standard textbooks which does not enrich learners' experience in a classroom. Instead, the classroom experience should provide an opportunity for students to learn through a process of conversation among themselves and with the teacher (Laurillard, 2002; Waite, Jackson, \& Diwan, 2003). Our classroom model supports Vygotskian classroom principles which are based on social constructivism theory. These principles state that "Learning and development is a social, collaborative activity", and "Classroom activity should be reality-based and applicable to the real world" (Vygotsky, 1978). This model is also supported by the emergence of a "Community of Practice" which promote learning processes by which people share ideas and strategies to build solutions and innovations as they interact (Lave \& Wenge, 1998; Brown, 1991). The purpose of the proposed framework is to facilitate the transition from formal school learning to real-life learning, in an attempt to assert "authentic learning", which is defined as situated learning whereby people retrieve and apply formal school learning in real-life (Herrington \& Oliver, 2000).

Conversational learning model requires communication channels that facilitate self-organization and interaction. To enable these channels, a technology-enhanced learning venue could empower teachers to provide resourced, coordinated and monitored learning spaces (Espey, 2008). We propose a studio-framework of a classroom as a learning venue where students constantly interact with peers and mentors to implement the proposed conversational learning model. This learning model promotes (1) Collaborative learning with peers, (2) Interaction with teacher or mentor to learn about concepts, (3) Cooperative learning to combine skills, and (4) 
Learning reflection or transfer to apply skills in other new situations. As shown in Fig. 1, the proposed learning spaces integrate essentially four areas in one common classroom: Lecture Area, Collaborative Work Area, Workgroup Area and finally a Transfer Area. The lecture area grabs the attention of all classroom learners into conceptualization of knowledge. It may also serve as a compilation of works done by the classroom groups to contrast solutions/inputs among different groups. In either case, this learning space is expected to extend subjective experiences into conceptual generalizations as part of the learning process. Collaborative learning area combines skills to build a single-flow of a learning product (for example a solution to a problem or presentation of a case study). Workgroup area is a space for cooperative learning to share ideas or past experiences. Finally, the transfer area uses relevant external domains to experience learnt concepts in real contexts/ situations.

Classrooms are designed to meet current and future needs of teachers and students who will use them, rather than simply replicating what was done in past classrooms or making compromises that have a negative impact on the quality of the learning environment. Current classrooms are ill-designed to support conversational learning styles. Earlier research presented the concept of a collaborative computer integrated classroom specially designed to achieve a combination of interactive and collaborative learning in the context of the European NIMIS project (Hoppe et al., 2000). However, this approach does not support communication and suits only a particular category of students. Besides it is not grounded on the advocated principles of conversational theory (Scott, 2001). A technology-enhanced classroom model was set up at North Carolina State University as a prototype to transform education by allowing instructors to project any group of student's display alongside the instructor's display, or side-by-side with another group of students. This research aims too at demonstrating that a shared computer per team fosters student interaction (Beichner, 2006). However, this classroom model does not induce standard instructional patterns to systematically guide teachers who utilize the power of the provided technology. More recently, Iowa University housed a technology-rich classroom where stu-

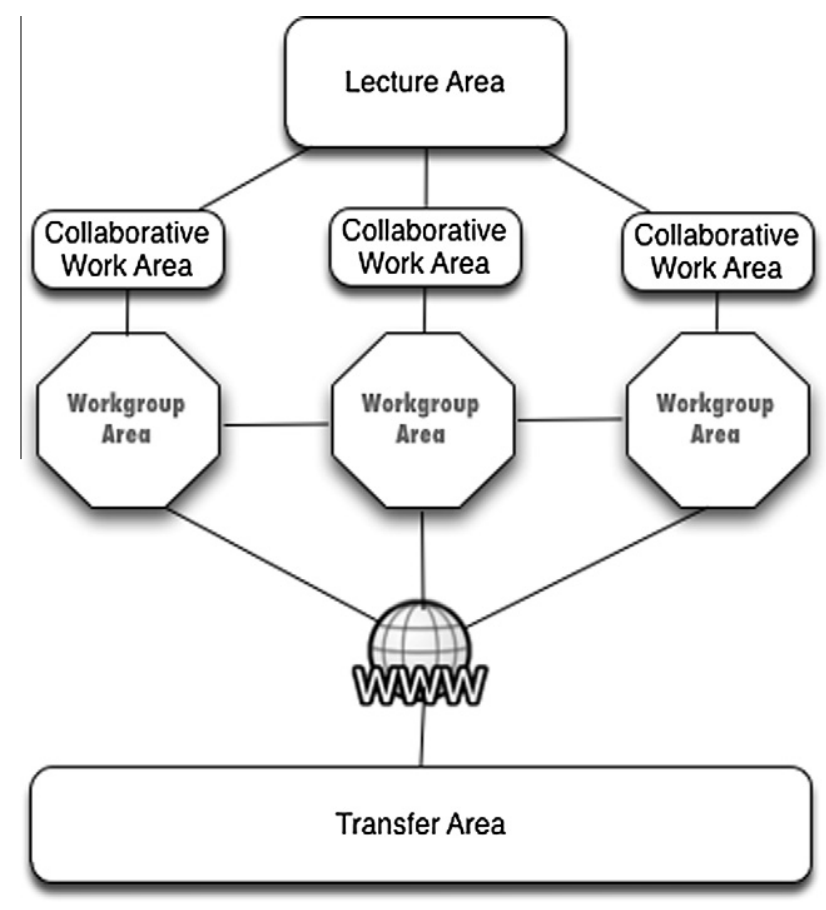

Fig. 1. Conversational learning spaces. dents are seated at six round tables placed evenly about the room, with the instructor's station located in the middle. Each table in the classroom is equipped with three laptops, with the expectation that each team of three students would share a single computer and display. Students can choose which of the three laptops will be projected on the display (Soderdahl, 2011). However, the classroom technology infrastructure is not supported by pedagogical grounds and does not specifically focus on conversational learning models.

As educational institutions are under pressure to keep pace with new developments in technologies, good pedagogy practice recommends a technology-supported classroom that maximizes discussion while limiting "noise" to foster cooperation, collaboration and knowledge sharing (Mäkitalo-Siegl, Zottmann, \& Kaplan, 2010). Current classroom design makes a judicious mix of education and technology disciplines to ensure that adequate attention is given to different types of instructional methods. The proposed approach in this paper facilitates reconfiguration of a learning environment and its related processes using the power of today's technologies.

The remaining sections of this paper are organized as follows. In Section 2, we describe the structure of our technology-enhanced classroom where we integrate the proposed implementation of a conversational learning design. Then, in Section 3, we discuss the learning dynamics that occur in this novel learning environment. In Section 4, we show an assessment methodology to continuously monitor learning retention in the proposed studio-classroom. In Section 5, we reveal performance indicators which we use to evaluate the outcomes of the proposed learning approach through a case study. Finally, we conclude the paper with a summary of the presented work in this paper and some future extensions to this work.

\section{Conversational learning design}

Conversational learning involves active learners in the process of customizing educational tools to trigger conversations in every learning situation. This domain-independent model is part of Gordon Pask's conversation theory which conceptualizes effective communication as the process of coming to know where one participant in a conversation can be said to understand another participant's "knowledge" (Pask, 1976). This process creates instances where "ideas, concepts and even whole chunks of knowledge are transported from a speaker to a listener ... rather each must abstract meanings, concepts and knowledge from his or own experience" (Scott, 2001). We employ key central entities of Pask's theory to frame our learning design, which are "conversations," "individuals" and "concepts" (Scott, 2009) and to elaborate related interaction scenarios. The main actors are student groups to trigger questions, teacher to offer explanations, class to apply and contrast knowledge and domain to transfer knowledge.

This learning model poses new requirements for instruction designers to develop learning environments or spaces which are capable of linking conversational learning practices with Information and Communication Technologies (ICT).

\subsection{Learning space}

Learning spaces encompass the places in which learning occurs, including physical and virtual virtual areas (Brown, 2005). Fig. 2 shows a model of a classroom, which provides a studio-framework as a conglomeration of learning spaces to respond to conversational learning requirements and related instruction processes. This self-contained model is currently implemented in our institution as a prototype classroom. It embodies three work areas for 


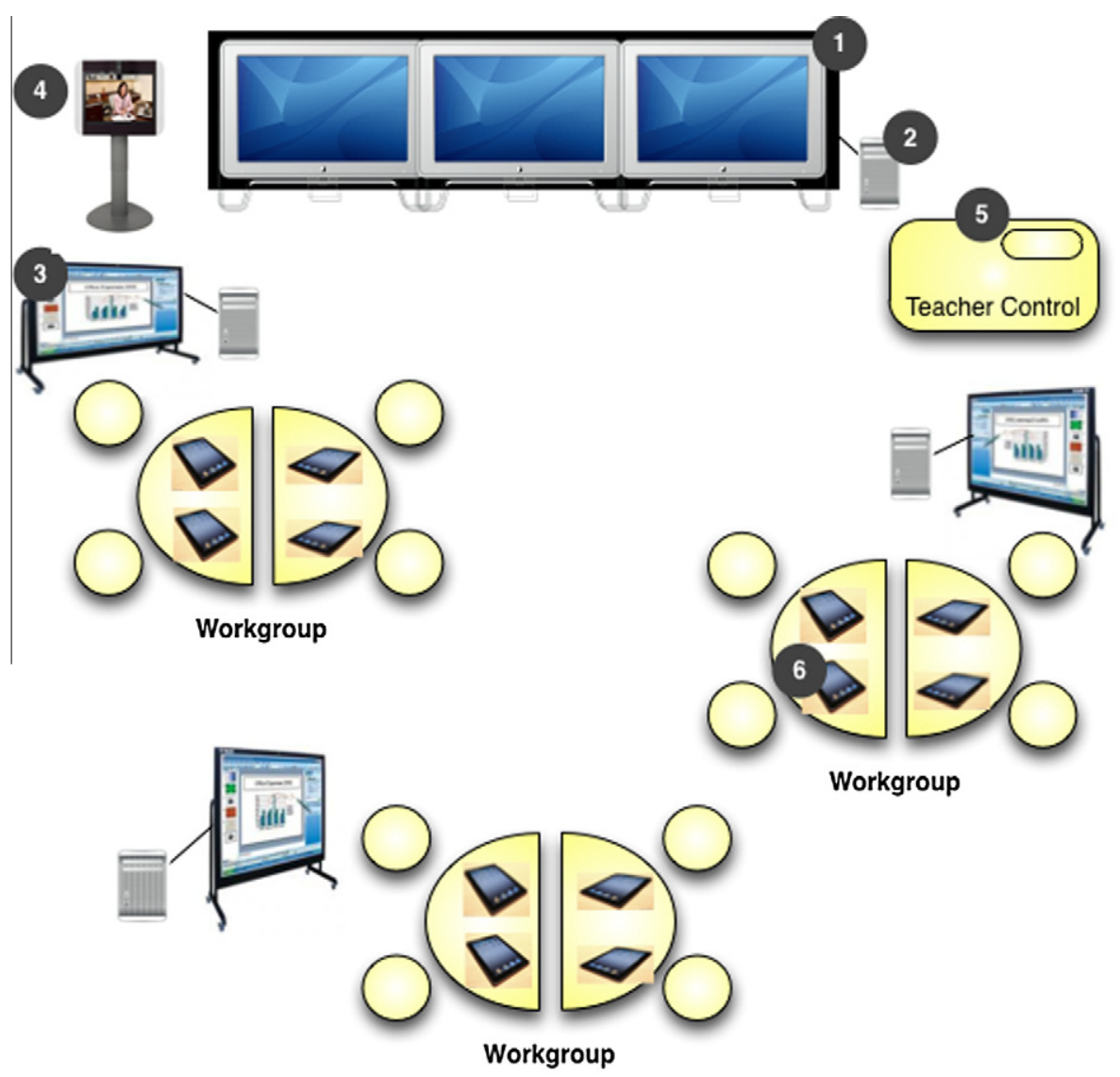
1 Wall-mounted extended touch screen (3 screens)
(4) Telepresence unit
2 Desktop Computer which controls the touch screen
(5) Teacher's control panel
3 Touch-board
(6) IPad

Fig. 2. Classroom layout.

students to nurture conversation. Each student is equipped with a tablet as a source of his e-books and even copybooks (using appropriate apps and a stylus pen). Tablets are increasingly being promoted as study aids and books repository. Besides, this tool presents a shareable whiteboard option that makes it possible to edit and see the others' annotations in real-time. We use this facility to support and track cooperation. Each group of students in the classroom (currently four to six per group) is also associated with a common large viewing area for the group members to collaborate on solving a single problem or developing a case study presentation. We use this facility of the classroom to combine learners' efforts into a collaborative task.

The teacher who is essentially orchestrating this environment, is also equipped with a three adjacent screens (that seamlessly appear as a single large screen) to contrast groupworks and conceptualize knowledge. This is the area where lecturing occurs. A control panel within the classroom allows the teacher to switch among classroom learning spaces. A mobile telepresence (or mobile videoconference) unit is used to implement learning reflection or transfer. The unit is equipped with a camera and a software to share contents with external parties. It allows learners to immerse with the external world that is relevant to their actual learning domain in order to apply and validate learnt concepts in real contexts. Other immersive learning approaches may be considered as well such as tangible interfaces (Sánchez, Riekki, \& Pyykkönen,
2009) to virtually bring the workplace into the learning space of the classroom (De Freitas et al., 2010). In both situations, the result is a platform where learning can be transferred to other (realistic) contexts.

\subsection{Learning design patterns}

To facilitate conversational learning content creation and reuse in the proposed classroom environment, we advocate the use of design patterns that translate best practices into conversational learning structures. We propose IMS Learning Design (IMS-LD) compliant templates for that purpose. IMS LD ${ }^{1}$ is a standard specification to specify all kind of learning activities and acts as a container framework of elements that can describe any design of teaching and learning model (Paquette et al., 2005). LD defines learning activities that include several roles playable by several actors in a defined environment (Durand \& Downes, 2009). IMS-LD may be compared to a script for a play, where participants play their roles as planned by the director. The subtle inclusion of "roles" and "learning environments" in IMS-LD (as an evolution from its IMS Simple Sequencing or IMS-SS predecessor), enables us to express activities with more than one role that take place in different learning

\footnotetext{
${ }^{1}$ http://www.imsglobal.org/learningdesign.
} 


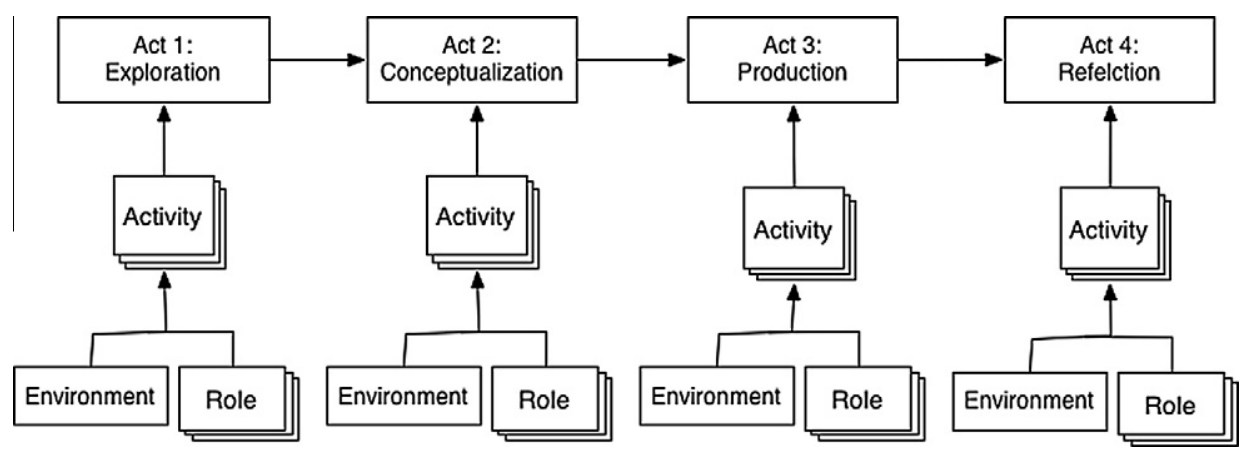

Fig. 3. Conversational learning design patterns.

environments. Hence, IMS-LD can express conversational learning activities where roles are assimilated to learners and mentors, and learning environment is represented by our proposed studioclassroom.

Teachers and instruction designers need a specification of conversational learning model to express related learning activities. An IMS-LD compliant specification lends itself to be used by existing graphical authoring tools and engines to play the resulting specifications (McAndrew, Nadolski, \& Little, 2005; Griffiths, Beauvoir, \& Sharples, 2008). To facilitate conversational learning developments, we propose ready-made templates that can be further refined to create finished modules (called learning units). These templates are then applied in conversational learning environments to guide instructors and content providers (Koper, 2005). We call these templates Conversational Learning Design Patterns (CLPs). They are analogous to Web page templates (e.g. available in Microsoft Front Page) to produce finished Web pages as content and structure are separated. Fig. 3 illustrates this IMS-LD based learning design pattern for our proposed conversational learning model. Conversational Learning Design Patterns or CLPs could be implemented using an appropriate editor. The provision of a dedicated high-level conversational learning editor guides teachers in the process of creating conversational learning units by starting from existing patterns.

To support the deployment of the proposed classroom design patterns, we have specifically designed a classroom environment as shown in Fig. 1 and further illustrated in the actual classroom layout shown in Fig. 2. The proposed classroom environment embeds learning spaces to contain activity instances for each pattern related activities as follows: the exploration activities are supported by "workgroup area", the conceptualization pattern is supported by "lecture area," the production pattern is supported by "collaborative work area" and finally the reflection pattern is supported by "transfer area" of the proposed technology-enhanced classroom.

\section{Conversational learning processes}

Conversational learning advocates cognitive and conceptual knowledge (i.e. "knowing why") as well as procedural and reflective knowledge (i.e. "knowing how") (Scott, 2001) at a group level. Research in social psychology had examined the positive effects of group interactions on individual performance (Olivera \& Straus, 2004). Members of a group may work independently at different stage of the proposed conversational learning cycle, and then combined-conversations produce a collective learning product. In this process, individuals get also the opportunity to influence group processes and outcomes, which is a desirable individual skill in today's increasingly connected society where individuals become inherently part of a network.
Our proposed conversational-learning classroom embraces these activities where learners thrive across transitional modes of conversational learning activities as they develop skills and knowledge, and immerse in real-life experiences (Long, 2005). Teacher's fundamental tasks are to get students to engage in these learning activities following a conversational learning cycle shown in Fig. 4. Conversation occurs at each of the following classroom learning phases: Exploration, Conceptualization, Production and Reflection. This cycle is an extension of "The Learning Cycle" developed earlier for the Science Curriculum Improvement Study (SCIS) (Karplus, 1971). This model is an inquiry-based instruction following three distinct phases: (1) Exploration which provides students with firsthand experiences and prior-knowledge sharing through interactions with peers and texts; (2) Conceptualization which introduces students to underlying concepts through interaction with teachers; (3) Concept application which asks students to apply these concepts to new situations or new problems. We have added to this model another phase, namely (4) Reflection to illustrate the concept in real, domain-specific context, in accordance with Vygotskian classroom principles which bring the concept into the real world (Vygotsky, 1978). Throughout the proposed instructional process, the teacher acts as project manager, tutor and lecturer (Mazen, Jones, \& Sergenian, 2000). Next, we illustrate conversation scenarios throughout the proposed conversational learning cycle.

The class starts by exploring the subject matter through a case study discussion. Group members share perspectives and experiences during this phase. This cooperative learning process produces a social knowledge that grows out of explicit ideas generated through past experiences and shared in conversations. Conceptualization of knowledge occurs then as offspring of the multiple conversations conducted within and among groups, under the mentorship of the teacher who facilitates the conversation and keep it focused towards desired concepts (De Oliveira Fontes, Neto, Pontes, \& de Lima Campos, 2011). This initial classroomlearning phase is conducted in a wiki-like contribution from group members whereby each member has an individual perception to share within a group context.

Next, the teacher may expose groupworks to contrast solutions and insights as an evolution towards a larger conversation (across groups) by the analysis of the explicit records of participants' conversation. This instruction practice distinguishes between the personal knowledge construction and the influence of social knowledge, which mutually shape each other through conversations (Olivera \& Straus, 2004). A collaborative learning practice forms the next phase of the classroom instruction through the production of solutions to problems via conversations (Baker, Jensen, \& Kolb, 2005). Towards that end, this phase is performed collaboratively within each class group. We distinguish between the exploratory groupwork in the first phase and the collaborative 


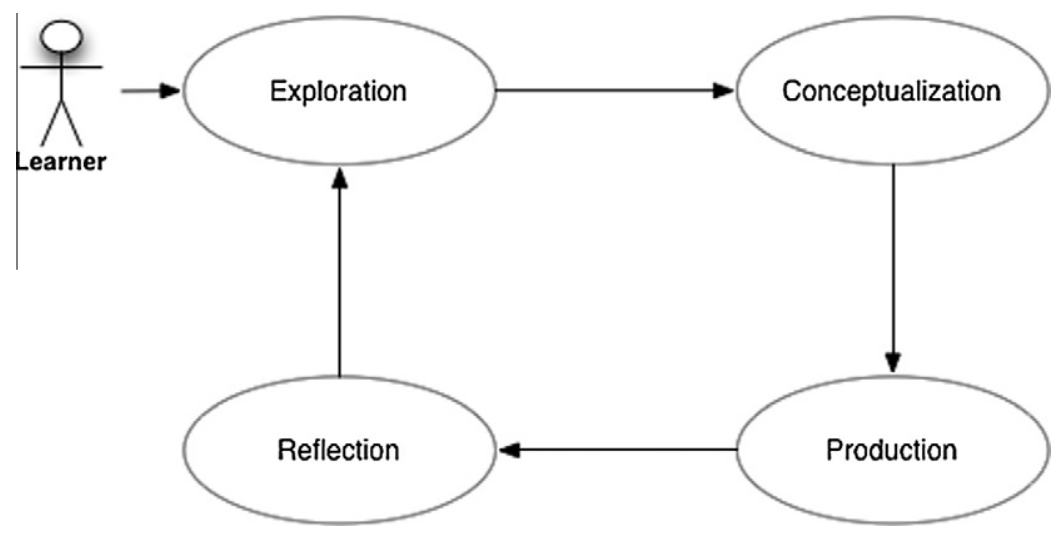

Fig. 4. Conversational learning cycle.

production in this third phase, which results in solutions to problems or identifying new opportunities based on previously acquired concepts (Dillenbourg, 1999; Barkley, Cross, \& Major, 2004). Unlike the wiki-like learning space (Johnson \& Lomas, 2005) of the exploratory phase, in the production phase, group members share a common platform that is tied to a single source to control the sequence of learning production. For example, the product could be steps to solve a problem or a presentation to report the implication of applying a concept to a specific domain. The single flow involved in the production process results from a cumulative thought following a deeper level of conversational learning. Finally, the transfer phase immerses learners in an experiential learning environment to validate the achieved product from the previous phase (as shown in Fig. 4). Several patterns of experiential learning have been advocated (Baker et al., 2005) for which, we already provided digital representations in a previous research (Atif, 2011). These learning patterns are deemed to be responsive to contextual demands and provide "a sense of being there" to learners either to transfer concepts to practical, possibly work-related environments, or to bring the work-environment into the classroom through some tangible interfaces (Do-Lenh, Jermann, \& Cuendet, 2010).

\section{Conversational learning assessment}

As discussed earlier, conversational learning provides a shared space for learners to engage collaboratively towards knowledge construction in a narrative-rich environment. The proposed studio-classroom motivates and preserves conversation flows between learners and their teachers, and also among learners, whilst being potentially immersed in related domains. Any educational program which incorporates the proposed conversational learning model requires assessment and evaluation to monitor learning performance. We introduce an electronic assessment framework and the related information system implementation which articulates learning objectives, lesson outcomes and related assessment workflows (Gardiner, 2002). Using this assessment approach, we can conduct experiments to answer challenges facing education providers to figure out the extent of learning outcomes coverage and evaluate learning gains that happened in the proposed technology-enhanced classroom. Answers to these assessment queries facilitate decision-making processes to correct possible shortcomings.

In the proposed studio-based environment, an e-portfolio of work from each individual learner is used as an assessment instrument. As students undertake studio-enabled works collaboratively, they gain skills in collaboration and communication, and immerse in context-specific domains. During the class sessions, students collect and correlate items that reflect what they have been learning, and their development as group members. E-portfolio are enriched by students throughout the semester and assessed on at least two occasions by tutors (for the purpose of experimenting the proposed conversational learning model). Students maintain their e-portfolios for the duration of the class (Bhattacharya \& Hartnett, 2007) via a Web-based application. Several previous research efforts supported the use of portfolios to assess learning. Accordingly, it was stated that e-portfolio connects learning and assessment (Cambridge, 2010; Lin, Yuan, \& Liu, 200; Yancey, 2009). Another research validates the use of an e-portfolio in support of the assessment of both the learning process and product (Coric, Balaban, \& Bubas, 2011) and shifts the emphasis towards students' reflection of their own progress (Lee \& Chan, 2006; Abrami \& Barrett, 2005).

In the proposed conversational classroom environment, learning cannot be assessed in short durations using assessment tools like spot tests. There is a need for a broader range of assessment tools (Simon \& Forgette-Giroux, 2000) that could assess students' conversational lifecycle in terms of (1) Cognitive skills such as problem solving, and critical thinking (in exploration phase); (2) Affective skills which reflects their tendency to apply the targeted competency (in reflection phase); (3) Behavioral performance which assess the actual competency in practice as the student is performing it (in production phase); and finally, (4) Level of competency achievement as compared to the related stated outcome (in conceptualization phase). The portfolio contains an assessment tool entry for each phase of conversational learning integrated at design time as shown in Fig. 5. Each Learning Outcome (LO) of the subject matter is mapped at design time to any of the conversational learning module through the integration of an appropriate assessment tool as shown in Fig. 5.

\section{Case study and evaluation}

From the instructor's view, learning design could be performed through a visual 'drag-and-drop' authoring editor based on an "integration by reuse approach" (Hernandez-Leo, Harrer, \& Dodero, 2007) to repurpose contents to a range of educational contexts as shown in Fig. 6 . The same assembly approach guided the design of a sample course used in experimenting our implementation of the proposed conversational learning model in the suggested studio classroom.

The experimental course design converted an existing course entitled "E-Business Models" into a conversational learning approach. The first learning unit of the course is an Overview of E-Commerce and contributes to the following course outcome "Ability to identify various e-business models". The Exploratory 


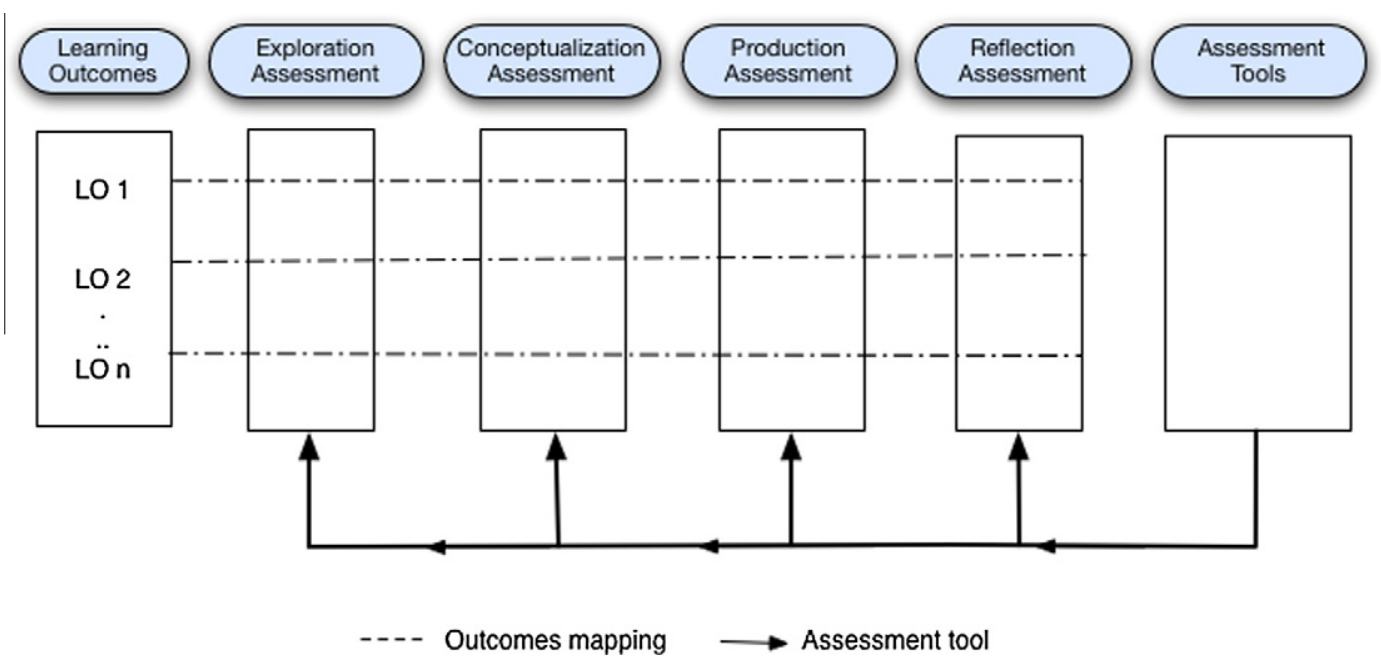

Fig. 5. Assessment integration.

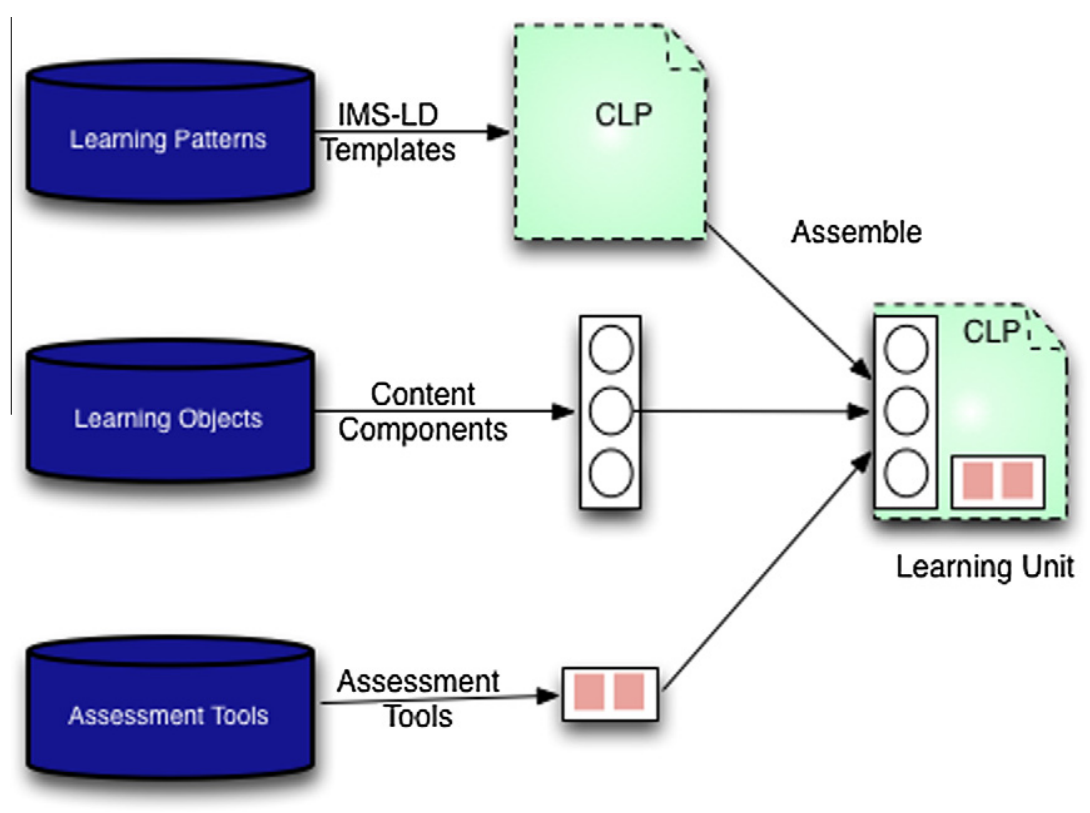

Fig. 6. Integration by reuse authoring.

phase consists in identifying "The Problems or Opportunities", "The Solutions" and "The Results" of adopting a given E-Business Model. The CLP design template for this course suggests a group discussion about an existing online business case. The instructor matched this suggested design-guide with airline business e-services. Using their individual iPads, group members entered the exploratory mode to scribble cooperatively notes about the stated exploratory phase categories (i.e. Opportunities, Problems, Solutions and Results of adopting e-services in airline business). One group member whose father worked at the local "Emirates Airline" shared with peers the motivation of that airline to move on-line earlier as the result of increasing competition and increasing airport charges. This reference to problems faced earlier by the airline led to the requirement of a larger customer base (i.e. opportunity) and the need to develop rich e-services for attracting more customers as a potential solution. Another group member, continued on the same flow and shared with peers his awareness about Emirates Aviation College (based in Dubai) used to train the company personnel (as a business to employee online solution). Another group member who googled-out Emirates Group found the company's initiative to join an on-line procurement marketplace (called "tejari"), and finally another one who travelled on the airline recalled making a donation to the Emirates Foundation (as a business to community online approach).

The instructor then indicated the move to the next step in the learning cycle using the classroom control panel (Component 5 in Fig. 2), by pulling out the "Conceptualization" learning unit which pattern suggests to start by contrasting the individual group findings on the extended board screen (Component 1 in Fig. 2) as a prelude to enter the Lecture mode. Through the design pattern, instructor is guided to extract relevant concepts which in this case are (based on the exploratory phase findings): Business-To-Consumer (e,g, booking e-services), Business-To-Business (e.g. the procurement marketplace), Business-To-Employee (e.g. the Aviation College e-training) and Business-To-Community (e.g. the Foundation). The lecture mode revealed formal definitions of these e-business models.

The instructor asks then groups to analyze the implications of online business-models adoption on a set of given e-business case studies. Each group was assigned a different case study which 
Table 1

Assessment indicators.

\begin{tabular}{|c|c|c|}
\hline Indicator & Description & Example \\
\hline Cognitive & Knowledge needed to apply the competency, e.g. problem solving strategies & Stated summary about different problem solving strategies \\
\hline Affective & $\begin{array}{l}\text { Tendency to apply the competency, e.g. self-confidence in ability to solve } \\
\text { problems }\end{array}$ & Rating-scale on self-confidence in performing class work \\
\hline Behavioral & Performance of the competency as it is applied, e.g. actually solving a problem & Rating-scale on the competency level \\
\hline Developmental & $\begin{array}{l}\text { Description of achievement level of competency according to stated outcomes, } \\
\text { e.g. descriptive scale checked out regularly }\end{array}$ & $\begin{array}{l}\text { Level of achievement using a point-scale after first problem } \\
\text { solving attempt and another after three }\end{array}$ \\
\hline
\end{tabular}

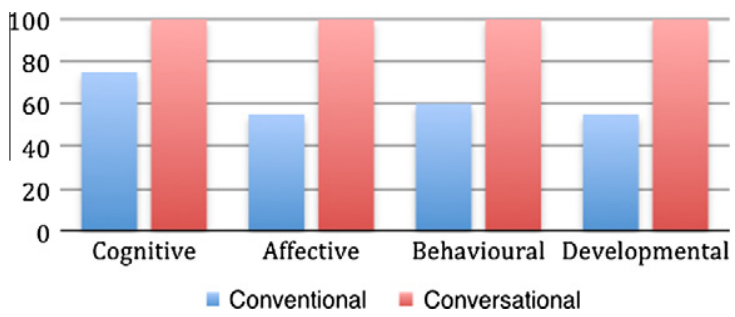

Fig. 7. Experiment results.

consists in the actual URL of suggested business websites. A group presentation which reveals the online business activity and the outcomes of this activity was expected. The class environment then entered the collaborative learning production mode of the conversational learning cycle and used the common group touchboard (Component 3 in Fig. 2) to collaboratively produce the expected presentation. Groups took then turns explaining their presentations. Finally, the Reflection phase of the Learning Cycle moved the class virtually to a local marketplace office named tejari.com via the classroom telepresence system (Component 4 in Fig. 2).

Following the above case study, an assessment experiment is conducted and compared with historical data from past assessment experiences based on conventional learning model in a traditional classroom for the same section of the course material. We use the performance indicators discussed in Section 4, and summarized in Table 1 with sample extracts from the e-portfolios (Simon \& Forgette-Giroux, 2000). The evaluation of learning outcomes achievement is embedded in the form of questionnaires at the end of each unit in the student portfolio. We used them as assessment tools for the broad assessment indicators discussed in Table 1. Examples of collected data are shown Table 1. After collecting the assessment data from those questionnaires, we reflected the results in Fig. 7.

The collected data from e-portfolios across the two classroom experiences are averaged and normalized. We selected the course outcome "Ability to identify various e-business models" as the assessed competency of the course outcome. Overall, and as shown in Fig. 7, the conversational learning approach in the proposed studio environment outperforms conventional classroom learning.

\section{Conclusion}

We presented a learning model labeled "conversational learning" which roots are based on education psychology fundamentals. We conceived a classroom environment based on a technology-enhanced studio-based layout. We have shown how this layout facilitates the deployment of a proposed conversational learning cycle in the suggested classroom configuration. We introduced design patterns as conversational-learning guides, based on standard learning design principles that facilitate a creation by reuse approach of conversational-learning contents. In an attempt to streamline the development of conversational learning units, we suggested an integration framework to assemble learning design, learning objects and their related assessment indicators. We have illustrated the resulting studio-classroom model through an actual case study. Then, we assessed the performance of this learning environment using that case study across two different student populations to compare empirically learning gains based on standard learning performance dimensions. The results show interesting tradeoffs favoring generally the conversational learning approach in the proposed studio-classroom over conventional learning in a regular classroom.

We plan to extend this work by further empowering the orchestration role of the instructor in conversational learning environments through the elaboration of further instructional templates and an appropriate authoring editor to guide content creation and instruction processes. We are also examining social Web means to implement the "Reflection" phase of the proposed Conversational Learning Cycle.

\section{References}

Abrami, P., Barrett, H. (2005). Directions for research and development on electronic portfolios. Canadian Journal of Learning and Technology/La Revue Canadienne De L'Apprentissage et De La Technologie, 31<http://www.cjlt.ca/index.php/cjlt/ article/view/92/86> Accessed 19.06.12.

Atif, Y. (2011). An architectural specification for a system to adapt to learning patterns. Education and Information Technologies, 16, 259-279.

Baker, A. C., Jensen, P. J., \& Kolb, D. A. (2005). Conversation as experiential learning. Management Learning, 36, 411-427.

Barkley, E. F., Cross, K. P., \& Major, C. H. (2004). Collaborative learning techniques: A handbook for college faculty (1st ed.). Jossey-Bass.

Beichner, R. (2006). North Carolina State University: SCALE-UP. Learning Spaces, 24, 29.1-29.6. <http://net.educause.edu/ir/library/pdf/P7102cs16.pdf> Accessed 15.06.12.

Bhattacharya, M., \& Hartnett, M. (2007). E-portfolio assessment in higher education. In 2007 37th annual frontiers in education conference - global engineering: knowledge without borders, opportunities without passports (pp. 19-24). IEEE.

Brown, J. (1991). Organizational learning and communities-of-practice: Toward a unified view of working, learning, and innovation. Organization Science, 2, 40-57.

Brown, M. (2005). Learning space design theory and practice. EDUCAUSE Review, 40.

Cambridge, D. (2010). E-portfolios for lifelong learning and assessment. Jossey-Bass.

Coric, A., Balaban, I., \& Bubas, G. (2011). Case studies of assessment ePortfolios. 14th International Conference on Interactive Collaborative Learning (ICL), 1, 89-94.

De Freitas, S. et al. (2010). Learning as immersive experiences: Using the fourdimensional framework for designing and evaluating immersive learning experiences in a virtual world. British Journal of Education Technology, 41, 69-95.

De Oliveira Fontes, L.M., Neto, F.M.M., Pontes, A. Á. A., de Lima Campos, G.A. (2011) An agent-based architecture for supporting the workgroups creation and the detection of out-of-context conversation on problem-based learning in virtual learning environments. In SAC '11: Proceedings of the 2011 ACM symposium on applied computing. ACM.

Dillenbourg, P. (1999). Collaborative learning: Cognitive and computational approaches. In Advances in learning and instruction series. Routledge.

Do-Lenh, S., Jermann, P., \& Cuendet, S. (2010). Task performance vs. learning outcomes: A study of a tangible user interface in the classroom. In 5th European conference on technology enhanced learning.

Durand, G., \& Downes, S. (2009). Toward simple learning design 2.0. In 4th International conference on computer science education, 2009. ICCSE '09 (pp. 894 -897). IEEE.

Espey, M. (2008). Does space matter? Classroom design and team-based learning. Applied Economic Perspectives and Policy, 30, 764-775.

Gardiner, L. F. (2002). Assessment essentials: Planning, implementing, and improving assessment in higher education. In (Book reviews): An article from: Journal of higher education. Ohio State University Press. 
Griffiths, D., Beauvoir, P., \& Sharples, P. (2008). Advances in Editors for IMS LD in the TENCompetence Project. In Eighth IEEE international conference on advanced learning technologies. IEEE Computer Society.

Hernandez-Leo, D., Harrer, A., \& Dodero, J. (2007). A framework for the conceptualization of approaches to Create-by-Reuse of learning design solutions. Journal of Universal Computer Science, 13, 991-1001.

Herrington, J., \& Oliver, R. (2000). An instructional design framework for authentic learning environments. Educational Technology Research and Development, 48, 23-48.

Hoppe, U., Lingnau, A., Machado, I., Paiva, A., Prada, R., Tewissen, F. 2000. Supporting collaborative activities in computer integrated classrooms - the NIMIS approach. In Sixth International workshop on groupware, 2000. CRIWG 2000 (pp. 94-101).

Johnson, C., \& Lomas, C. (2005). Design of the learning space: Learning and design principles. EDUCAUSE Review, 40.

Karplus, R. (1971). Readings in science education for the elementary school. In SCIS: The science curriculum improvement study. Macmillan.

Koper, R. (2005). Learning design: A handbook on modelling and delivering networked education and training. In An Introduction to Learning Design (pp. 3-20). Heidelberg: Springer.

Laurillard, D. (2002). Rethinking University Teaching: A conversational framework for the effective use of learning technologies. Routledge.

Lave, J., \& Wenge, E. (1998). Communities of practice. Cambridge University Press.

Lee, E., \& Chan, C. (2006). Students assessing their own collaborative knowledge building. International Journal of Computer-Supported Collaborative Learning, Springer, 1, 57-87.

Lin, H.T., Yuan, S.-M., \& Liu, Z.F. (2004). The construction of Web-based portfolio system. In Proceedings of the FIfth international conference on information technology based higher education and training, 2004. ITHET 2004 (pp. 284-286).

Long, P. D. (2005). Learning space design in action. EDUCAUSE Review, 40.

Mäkitalo-Siegl, K., Zottmann, J., \& Kaplan, F. (2010). Classroom of the future. In Orchestrating collaborative spaces. Sense Publishers.

Mazen, A. M., Jones, M. C., \& Sergenian, G. K. (2000). Transforming the class into a learning organization. Management Learning, 31, 147-161.

McAndrew, P., Nadolski, R., Little, A. (2005). Developing an approach for learning design players. Special Issue: Advances in Learning Design of Journal of Interactive Media in Education, 1. <http://www-jime.open.ac.uk/article/2005-14/287> Accessed 19.06.12
Olivera, F., \& Straus, S. G. (2004). Group-to-individual transfer of learning: Cognitive and social factors. Small Group Research, 35, 440-465.

Paquette, G., Marino, O., De la Teja, I., Lonard, M., Lundgren-Cayrol, K., \& Contamines, J. (2005). Implementation and deployment of the IMS learning design specification. Canadian Journal of Learning and Technology/La revue canadienne de l'apprentissage et de la technologie, 31.

Pask, G. (1976). Conversation theory: Applications in education and epistemology. Amsterdam: Elsevier.

Richtel, M. (2011). In Classroom of future, stagnant scores (vol. 1). The New York Times. <http://www.nytimes.com/2011/09/04/technology/technology-inschools-faces-questions-on-value.html?pagewanted=all> Accessed 19.06.12.

Sánchez, I., Riekki, J., \& Pyykkönen, M. (2009). Touch \& compose: Physical use interface for application composition in smart environments (web of things). In Proceedings of the 1st Int. IEEE workshop on near field communication (pp. 61-66).

Schrum, L., \& Levin, B. B. (2010). Leading 21st-century schools. In Harnessing technology for engagement and achievement. Corwin Press.

Scott, B. (2001). Gordon Pask's conversation theory: A domain independent constructivist model of human knowing. Foundations of Science, 6, 343-360.

Scott, B. (2009). Conversation, individuals and concepts: Some key concepts in Gordon Pask's interaction of actors and conversation theories. Constructivist Foundations, 4, 151-158.

Simon, M., \& Forgette-Giroux, R. (2000). Impact of a content selection framework on portfolio assessment at the classroom level. Assessment in Education: Principles, Policy E' Practice, 7, 83-100.

Soderdahl, P. A. (2011). Library classroom renovated as an active learning classroom. Library Hi Tech (), 29, 83-90.

Tantatsanawong, P., Kawtrakul, A., \& Lertwipatrakul, W. (2011). Enabling future education with smart services. In Annual SRII global conference (SRII) (pp. 550556).

Vygotsky, L. (1978). Mind in society. Harvard University Press.

Waite, W. M., Jackson, M. H., \& Diwan, A. (2003). The conversational classroom. In SIGCSE '03: Proceedings of the 34th SIGCSE technical symposium on computer science education. ACM.

Yancey, K. (2009). Electronic portfolios a decade into the twenty-first century: What we know, what we need to know. Peer Review, Association of American Colleges and Universities, 11 